\title{
Falência econômica das indústrias de Mato Grosso: uma análise de perfil e espacialidade
}

De acordo com registros da Junta Comercial do Estado de Mato Grosso (JUCEMAT), o número de indústrias falidas aumentou $57 \%$ e ultrapassou o montante de 15 mil, entre 2006 e 2016. Trata-se de um número elevado, a ponto de questionar-se quais particularidades estão relacionadas com a falência econômica neste setor, no estado. Por isso, o objetivo principal deste estudo consiste em avaliar o perfil das indústrias que encerraram suas atividades no período, considerando a estimativa da taxa de sobrevivência para os segmentos de extração e transformação. Os principais resultados apontam para consequências generalizadas oriundas das principais crises econômicas, com efeitos mais agressivos para as microempresas de extração de areia, cascalho e pedregulho. Também, agravou os problemas das indústrias alimentícias e madeireiras, principais atividades da economia local, com impactos mais acentuados nas Regiões Sul, Sudeste, Norte e Centro-Norte de Mato Grosso. A taxa de sobrevivência diminuiu consideravelmente no período 2006-2008 e, apesar de recuperação no período seguinte, ainda não recobrou seu melhor desempenho, tanto no segmento de extração, quanto no de transformação.

Palavras-chave: Falência Econômica; Indústria; Taxa de Sobrevivência; Mato Grosso.

\section{Economic bankruptcy of Mato Grosso's industries: an analysis of profile and spatiality}

\begin{abstract}
According to records of the Commercial Registry of the Mato Grosso State (JUCEMAT), the number of bankrupted industries increased $57 \%$ and exceeded 15,000 between 2006 and 2016. It is an elevated number to the point of question what is particularities are related with the economic bankruptcy in this sector, in the state. Therefore, the main objective of this study consists in to evaluate the profile of the industries that ended their activities in the period, considering the survival rate estimate for the extraction and transformation segments. The main results show the generalized consequences, derived of the main economic crises, with more aggressive effects for microenterprises of sand, gravel and boulder extraction. It also aggravated the problems of the food and timber industries, the main activities of the local economy, with more accentuated impacts in the South, Southeast, North and Central-North regions of Mato Grosso. The survival rate has decreased considerably in the period 2006-2008; despite recovery in the next period, did not yet retrieve your best performance, so much in the extraction segment, how much in the transformation.
\end{abstract}

Keywords: Economic Bankrupt; Industry; Survival Rate; Mato Grosso.

Topic: Planejamento, Estratégia e Competitividade

Reviewed anonymously in the process of blind peer.
Received: 10/09/2018

Approved: $12 / 12 / 2018$
Dilamar Dallemole (iD

Universidade Federal de Mato Grosso, Brasil

http://lattes.cnpq.br/2556871852182132

http://orcid.org/0000-0001-7486-9786

ddallemole@gmail.com

\section{Katiane Toldi (iD)}

Universidade Federal de Mato Grosso, Brasil

http://lattes.cnpq.br/4732056636137344

http://orcid.org/0000-0003-2981-2670

katitoldi@hotmail.com

Arturo Alejandro Zavala

Universidade Federal de Mato Grosso, Brasil

http://lattes.cnpq.br/0725525983034054

http://orcid.org/0000-0002-8057-6135

zavala.arturo@gmail.com

\section{Alexandre Magno de Melo Faria (iD \\ Universidade Federal de Mato Grosso, Brasil \\ http://lattes.cnpq.br/9382990116776293 \\ http://orcid.org/0000-0001-6584-1925 \\ dr.melofaria@gmail.com}

Referencing this:

DALLEMOLE, D.; TOLDI, K.; ZAVALA, A. A.; FARIA, A. M. M.. Falência econômica das indústrias de Mato Grosso: uma análise de perfil e espacialidade. Revista Brasileira de Administração Científica, v.9, n.3, p.13-24, 2018. DOI: http://doi.org/10.6008/CBPC2179$\underline{684 X .2018 .003 .0002}$ 


\section{INTRODUÇÃO}

Dados da Junta Comercial de Mato Grosso (JUCEMAT) indicam que o número de empresas que encerraram atividades no estado aumentou em 57\% entre 2006 e 2016, ultrapassando o montante de 15 mil. Sejam de transformação ou extração, classificam-se em três grupos distintos: extintas, canceladas e falidas. Nas extintas, os proprietários decidiram encerrar suas atividades; nas canceladas, estão aquelas que ficaram mais de 10 anos sem fazer registros na Junta Comercial e as falidas são as que apresentam falência judicial. Há indicação de que a maioria das empresas que encerraram atividades são de pequeno ou médio porte, devido ao fato de não possuir a consistência empresarial mínima para enfrentar uma concorrência mais globalizada.

O crescimento do setor industrial deveria apresentar-se com uma consequência natural do agronegócio, fortemente promovido em Mato Grosso. A agregação de valor aos produtos primários e a exploração da vantagem comparativa local deveria tornar o estado mais competitivo, ao considerar que o setor industrial seria capaz de desenvolver esta competitividade de forma mais efetiva e menos dependente. Dados do Instituto Brasileiro de Geografia e Estatística (IBGE) apontam aumento do valor corrente do PIB industrial no estado, atingindo cerca de 15,8 bilhões de reais em 2014. Em 2015, as indústrias de transformação representavam $97,5 \%$ do setor no estado, valores representativos, contudo, no período a participação no PIB permanece em torno de $16 \%$, fato que reforça a necessidade de desenvolvimento do setor industrial de Mato Grosso.

Essa participação incipiente no PIB pode ser explicada por um grupo considerável de elementos geradores de risco e responsáveis pelas dificuldades à permanência das empresas em determinados mercados globalizados. Algumas hipóteses podem ser arroladas como fatores capazes de desencadear a falência econômica nas empresas, ao se considerar as diversas dificuldades enfrentadas pelo setor industrial em Mato Grosso. Custos operacionais podem interferir na competitividade devido a estrutura logística precária, independente do fator localização. Outra hipótese são os problemas de gestão, na qual as empresas não estão preparadas para gerir, planejar e sobreviver às mudanças constantes no mercado, que está cada dia mais competitivo. Ainda, entre os fatores geradores de falência, destacam-se os desentendimentos entre sócios e administradores, fraudes, erros estratégicos, além do falecimento de sócios e administradores ou a falência de clientes e/ou fornecedores importantes. Outros limitadores estão atrelados a capital de giro insuficiente, excesso de estoque e linha de produtos obsoletos (TOLEDO et al., 2012).

São elementos que impactam diretamente na capacidade das empresas em atingir níveis elevados de produtividade, que determinam seu padrão de sobrevivência local, além do aprimoramento para competir e sustentar o crescimento de sua produção. O conceito de competição pode incluir mercados segmentados, produtos diferenciados, diversidades tecnológicas e economias de escala. Trata-se de um papel claro e que não pode ser confundido com a função do Estado, ao qual sugere-se apenas encorajar, ou mesmo impedir as empresas de elevar seu desempenho competitivo de forma indireta, propor iniciativas tecnológicas pioneiras, acelerar o ritmo das inovações, entre outras medidas de defesa da concorrência. Ao 
considerar a capacidade destes agentes em desempenhar suas atribuições, pode-se determinar um padrão de sobrevivência das indústrias no mercado, condição que corrobora com o principal questionamento deste estudo: quais particularidades estão relacionadas com a falência econômica das industrias de Mato Grosso, considerando o porte, a diversidade das atividades econômicas, a distribuição espacial e qual a sobrevivência das mesmas.

Neste contexto, o objetivo principal consiste em analisar do perfil das indústrias que apresentaram falência econômica em Mato Grosso, entre 2006 e 2016, considerando a estimativa da taxa de sobrevivência, com base em dados documentais concedidos pela JUCEMAT. Trata-se de uma contribuição pioneira e alguns aspectos podem se tornar relevantes para o setor industrial mato-grossense. Saber qual estrutura é mais penalizada, quais setores ou regiões registram maior dificuldade pode orientar os agentes econômicos a promover ações mais específicas para atender demandas pontuais e auxiliar de forma mais eficiente na consolidação das estruturas.

Identificar as principais características tendências de falências e associá-las ao comportamento do mercado é fundamental para prever mudanças, ameaças e desenvolver estratégias, uma vez que se apresenta cada vez mais complexo, turbulento e inter-relacionado, tornando-se assim, um desafio a identificação de oportunidades. O entendimento de todo escopo e estrutura do mercado é fundamental, mesmo que o os interesses da organização se concentrem em um ou em poucos segmentos. Torna-se necessário considerar aspectos como as mudanças tecnológicas, a competição e a diversidade, em preferência àquela relacionada aos compradores

\section{REVISÃO TEÓRICA}

\section{O Conceito de Falência Econômica}

A falência econômica de uma empresa ocorre a partir do momento em que o valor do fluxo de caixa é inferior ao valor do passivo, fato que impossibilita o pagamento de credores, por exemplo. Exprime uma falha do negócio, que pode incluir mudanças de propriedade, alteração de ramos de atividade, fusões ou mesmo encerramento definitivo por decisão do proprietário. Esta incapacidade de pagamento de compromissos por parte das empresas leva a acumulação de perdas, algo que pode afetar credores, contudo, algumas optam pelo processo legal, numa espécie de reconhecimento da dívida e comprometimento com seus credores. Outras, simplesmente deixam de operar devido a incapacidade de pagamento de suas obrigações, seja de forma planejada ou não (WILCOX, 1971).

A probabilidade de falência econômica aumenta a partir do momento em que a empresa acumula resultados líquidos negativos em períodos contínuos, sem qualquer medida eficaz para frear tal tendência. Trata-se de uma situação que pode ser agravada, ou mesmo desencadeada, pelo mercado, ou seja, em uma recessão econômica pode não ser possível implementar ações para impedir o enfraquecimento da empresa. Neste caso, o risco passa a ser sistêmico e afetar todo um setor, cujos efeitos negativos costumam ser maiores entre as empresas mais fracas ou menos estruturadas (WESTGAARD et al., 2001). 
Contudo, as falhas costumam estar associadas a capacidade de gestão empresarial, uma vez que empresas são criadas diariamente, da mesma forma em que são encerradas, numa espécie de ciclo, que nem sempre é planejado ou gerido de forma eficiente. Entretanto, este processo é considerado importante para o aprendizado, uma vez que reflete na experiência do empreendedor, de forma a auxiliar no combate à má gestão ou outros vícios que comprometem o sucesso empresarial (COPE, 2011). Independentemente de o problema estar relacionado ao mercado, ou aos processos internos das empresas, qualquer evolução é baseada no sucesso das rotinas, muitas vezes resultado de sucessivos erros de interpretação ou procedimento. De forma oportuna, empresários pode se valer dos erros passados para obter sucessos em novas empresas, tornando-se mais forte para enfrentar problemas futuros.

Ainda, em relação à gestão, cinco fatores são importantes, bem como, considerados estágios de crescimento de uma organização: i) a existência, fase em que a empresa necessita consolidar a demanda e, para isso, precisa conquistar a aceitação dos clientes; ii) a sobrevivência, com a equalização entre receitas e despesas, planejamento mínimo em relação ao fluxo de caixa e funcionários para que a empresa possa crescer; iii) o sucesso, com a expansão estável e rentável da empresa; iv) a decolagem, em que a empresa deve buscar recursos para crescer rapidamente, mesmo influenciada pelo mercado ou fatores macroeconômicos e v) a maturidade, com a consolidação dos ganhos financeiros, expansão da capacidade gerencial e manutenção das vantagens em relação aos concorrentes (CHURCHILL et al., 1983).

Em termos gerais, a falta de conhecimento administrativo e de mercado são importantes razões do insucesso empresarial que, muitas vezes, decorre a inexperiência e resulta em sucessivos erros de planejamento. Pelos mesmos motivos decorrem problemas de cunho financeiro e tecnológico, como a insuficiência de capital para iniciar ou manter o negócio, algo que pode originar problemas mercadológicos como ineficiência de marketing e vendas. No segundo caso, os problemas podem estar relacionados a qualidade do produto, tornando-os obsoletos, algo que certamente causará a perda de espaço frente aos concorrentes. Dentre as principais falhas listadas, cabe destacar a incapacidade do empreendedor em $72 \%$ dos casos, resultado da inexperiência e a falta de planejamento para gerir o negócio (DEGEN, 2005; CHIAVENATO, 2008).

A falência das indústrias também é resultado da atividade econômica, do ciclo de negócios e da política macroeconômica. Por mais que haja inexperiência ou incapacidade gerencial, muitas vezes, a relação com grandes fornecedores e clientes pode causar imposições não suportadas nos médio e longo prazos, por falta de crédito, mão-de-obra ou mesmo uma imposição de preços desfavoráveis. Trata-se de um problema mais evidente entre as micro e pequenas empresas, cujas estruturas são menores e dificilmente suportam grandes negócios sem o devido aporte financeiro para expansão e/ou capital de giro (CHÉR, 1991). Além do mais, o movimento dos concorrentes no mercado pode alterar sua condição no mercado, algo que demanda constante avaliação e previsão de oportunidades e desafios futuros, ou seja, novas estratégia para fazer frente às mudanças que tendem a ocorrer no mercado.

Ainda, em se tratando de micro e pequenas empresas, bem como, as contribuições da Teoria Microeconômica, fica claro a predisposição de uma estrutura de concorrência perfeita, em que a influência 
não ocorre por uma ou outra empresa, mas sim pelos preços determinados pelo mercado. Pelo fato de existirem muitos vendedores e compradores, a decisão individual tende a não afetar o preço de equilíbrio, de modo que cada empresa decide a quantia ofertada com base nos custos de produção. Nesta estrutura de mercado, supõem-se a disposição de produtos homogêneos, transparência das condições aos participantes e, principalmente, liberdade de entrada e saída de empresas, neste caso determinada pela (in)capacidade de permanência (PINDYCK et al., 2010).

Em mercados de concorrencia perfeita o preço de equilíbrio é formado pela correlação entre oferta e demanda e os capitais circulam livremente entre os varios setores, direcionando-se de forma natural aos mais rentáveis. $O$ equilíbrio tende a ser alcançado, independentemente do tempo, em condições de lucros normais à longo prazo, quando a receita total tende a igualar os custos totais (PINDYCK et al., 2010). Qualquer lucro extraordinário responsável pela atração de novas empresas é eliminado, da mesma forma que os menos eficientes são excluídos do mercado, em uma espécie de ajustamento natural, em que a falência consiste apenas em uma etapa deste ciclo.

Assim, registram-se o surgimento, a mortalidade e a sobrevivência de empresas nos diversos setores da economia, sendo este último, um ponto importante para a estabilidade econômica. A Organisation for Economic Co-operation and Development (OECD) realiza estudos sobre taxa de mortalidade e sobrevivência das indústrias nos países membros, por meio de um cálculo básico, em que a taxa de mortalidade decorre da razão entre o número de empresas falida e empresas ativas. Este resultado, subtraído de uma unidade, expressa a taxa de sobrevivência, superiores a $80 \%$ em países como os Estados Unidos. A taxa de sobrevivência também apresenta uma relação inversa com o tempo, uma vez que, com o passar dos anos diminui a sobrevivência das empresas no mercado (OECD, 2017).

No Brasil isto não é diferente, como revelam estudos de Albuquerque (2013) e Paiva et al. (2013). Foram identificados problemas típicos em cada estágio de vida das empresas, ou seja, em relação ao dirigente, a empresa e ao ambiente, sendo necessário a redução de impostos e da burocracia, bem como, a ampliação do crédito e do acesso à tecnologia para minimizar a mortalidade precoce de micro e pequenas empresa. Outro aspecto importante identificado no Brasil é a falta de redes de cooperação entre empresa de uma mesma região, falta de planejamento e estratégias adequadas a ponto de, em alguns casos, a taxa de abertura ser semelhante a taxa de fechamento de empresas (ALVES et al., 2014). Em Mato Grosso não foram identificados trabalhos que avaliam a falência econômica das empresas, ou mesmo sobre alguns aspectos básicos relacionados à atividade econômica ou espaço. Neste caso, ainda não há como precisar os fatores responsáveis pelo infortúnio empresarial local, no entanto, alguns aspectos serão esclarecidos no presente estudo.

\section{METODOLOGIA}

Avaliar o mercado é uma tarefa complexa e vai além de anseios ou necessidades; requer estratégias, as quais serão eficientes a partir do momento em que os indivíduos envolvidos compreenderem seu propósito (MINTZBERG et al., 2006). A compreensão do mercado deriva do entendimento integrado do 
comportamento dos consumidores, merece atenção quanto a sua magnitude e abrangência. São elementos que definem o ambiente, a funcionalidade e as tendências, a partir das quais a avaliação poderá alcançar melhores níveis e oportunidades, bem como, diminuir a probabilidade de insucesso ou mesmo a falência econômica da empresa (TELLES, 2003).

Nesse sentido, quanto maior for a capacidade de avaliação e compreensão do mercado, mais adequadas serão as estratégias e melhores serão as taxas de sobrevivência das empresas. Em Mato Grosso não é diferente; dados da JUCEMAT comprovam a insolvência de 413 empresas de extração e 15.644 indústrias de transformação, entre 2006 e 2016, distribuídas em todas as regiões do estado. No primeiro grupo destacam-se empresas de extração e/ou beneficiamento de argila, areia, cascalho, minérios, metais preciosos, calcário, ferro, carvão e alumínio. No segundo grupo estão listadas, principalmente, indústrias de transformação de madeira, alimentos, vestuário, metal, reboques e carrocerias, dentre outros. Os dados disponibilizam informações quanto a localização, atividade econômica, porte e capital, bem como, a data de criação e encerramento das atividades.

Com base nos dados cadastrais, a estrutura analítica considera duas etapas distintas: a primeira voltase para a análise qualitativa dos dados das indústrias de extração e de transformação, economicamente falidas em Mato Grosso, no sentido de apresentar um perfil e destacar elementos ligados a instabilidade e a falência. A segunda etapa visa aprofundar a análise em relação a mortalidades, com a estimativa da taxa de sobrevivência das empresas, no período indicado e de forma evolutiva.

A organização e exposição dos dados em tabelas e figuras visam identificar o perfil das indústrias falidas no estado, a distribuição espacial e a identificação de quais regiões e atividades econômicas enfrentam os maiores problemas. No segundo momento, em complemento a esta avaliação, estimou-se a taxa de sobrevivência considerando um interstício de dois anos. Este estudo considera o número de indústrias em atividade, encerradas e com situação indeterminada (que não se encaixa em nenhuma das outras duas). A taxa de sobrevivência será estimada com base na metodologia do INE (2017), representada pela seguinte expressão:

$$
T S_{i}^{t+k}=\frac{S_{i}^{t+k}}{R_{i}^{t}} \times 100
$$

em que:

$S_{i}^{t+k}$ Sobrevivência da empresa $i$ ao final de $t+k, k=1,2, \ldots$ $R_{i}^{t}$ Nascimento de empresas $i$ no ano $t$.

A matriz empírica considerou as informações estratégicas disponibilizadas pela JUCEMAT, em relação às indústrias encerradas, no período de 2006 a 2016, em Mato Grosso. Os dados são apresentados e discutidos na seção de resultados que segue, com a identificação das principais particularidades relacionadas à falência econômica das indústrias de extração e transformação, relativas ao porte, atividade econômica, distribuição espacial e sobrevivência delas. 


\section{RESULTADOS E DISCUSSÃO}

\section{Falência das Indústrias de Mato Grosso}

O número de falências em Mato Grosso ajusta-se as principais tendências de crises, nacionais ou internacionais, como o subprime em 2007 e a crise político-econômica brasileira desencadeada ainda em 2014. Os valores expostos na Figura 1 indicam picos de falências de indústrias extrativas e de transformação, justamente, em períodos posteriores aos eventos citados. No caso do setor de extração, o pico pós-subprime ocorreu em 2010, com o registro de 60 indústrias falidas, contudo, em 2015 o efeito da crise nacional foi ainda mais devastador no estado. Cabe destacar também a crise do agronegócio mato-grossense, responsável por outro pico de falências em 2006.

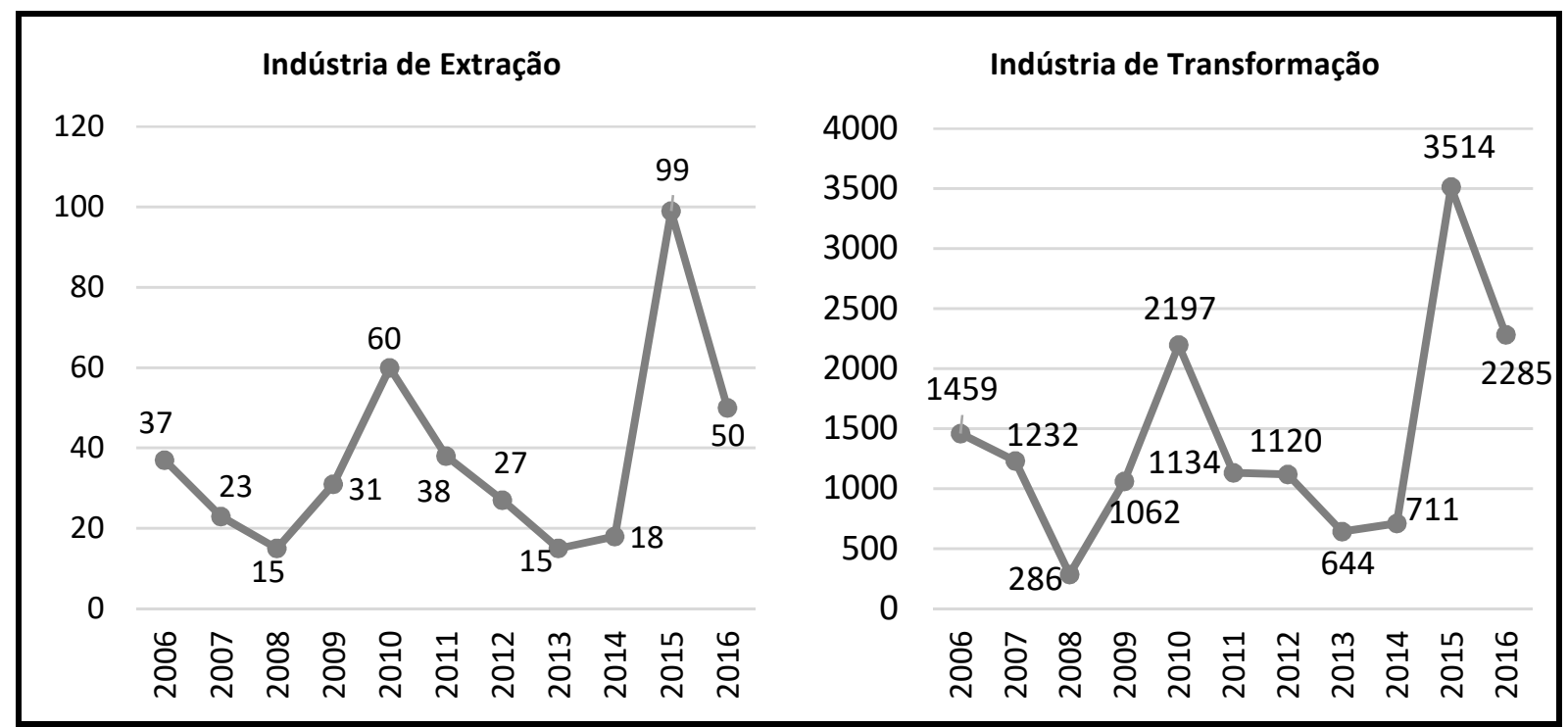

Figura 1: Número de Falências em Mato Grosso (2006-2016). Fonte: JUCEMAT (2017).

Em relação às indústrias de transformação, não há mudança no que se refere aos períodos de maior problema. Em 2006, 2010 e 2015 também são registrados os picos de falências deste grupo de empresa, o que reforça o efeito negativo destes três eventos em Mato Grosso. Em termos globais, foram registradas 405 e 15.644 encerramentos no setor de extração e transformação, respectivamente, entre 2006 e 2016. Destaca-se também, que os efeitos foram ainda mais agressivos para as microempresas, ao se considerar que $58 \%$ e $72,6 \%$ deste grupo de empresas falidas no estado atuavam no setor de extração e transformação, respectivamente (Tabela 1). O capital médio deste porte de empresas é de pouco mais de 27 mil dentre as extrativas e ainda menor entre as indústrias de transformação do estado.

Tabela 1: Porte e Capital Médio das Empresas Falidas (2006-2016).

\begin{tabular}{l|rr|rr}
\hline \multirow{2}{*}{ PORTE } & \multicolumn{2}{|c|}{ EXTRAÇÃO } & \multicolumn{2}{c}{ TRANSFORMAÇÃO } \\
\cline { 2 - 5 } & Falências & Capital & Falências & Capital \\
\hline Microempresa & $58,0 \%$ & 27.054 & $72,6 \%$ & 17.026 \\
Pequeno Porte & $6,2 \%$ & 50.916 & $4,6 \%$ & 83.655 \\
Médio/Grande & $37,8 \%$ & 319.244 & $22,9 \%$ & 401.125 \\
\hline
\end{tabular}

Fonte: JUCEMAT (2017). 
As empresas de médio e grande porte também foram significativamente impactadas no período. Neste grupo, registraram-se capitais médios superiores a 319 e 401 mil para as 37,8\% e 22,9\% empresas de extração e transformação, respectivamente, que deixaram de operar em Mato Grosso entre 2006 e 2016. Dentre as principais atividades extrativas do estado, o maior impacto foi no segmento de extração de areia, cascalho e pedregulho, que representou um quarto das falências, como pode ser observado na Figura 2.

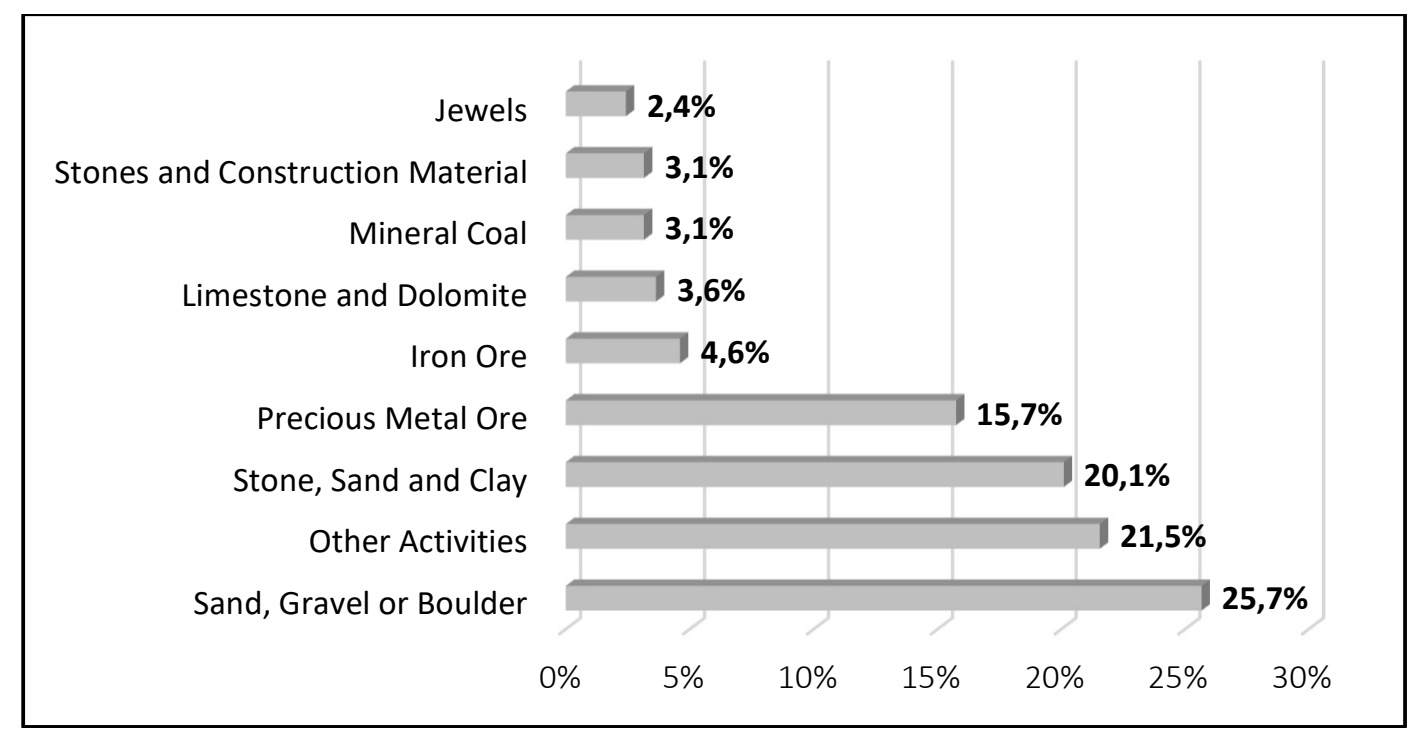

Figura 2: Atividade Econômica das Indústrias de Extração (2006-2016). Fonte: JUCEMAT (2017).

As atividades de extração de pedra, areia e argila (20,1\%), bem como, minério de materiais preciosos $(15,7 \%)$ também se destacam entre as mais impactadas em Mato Grosso. Também, cabe registrar os impactos nos setores de minério de ferro, calcário e dolomita, carvão mineral, pedras e materiais de construção, além de gemas, cujos encerramentos representam mais de $16 \%$ no período. Já, com relação às indústrias de transformação encerradas, 20,9\% pertenciam ao segmento de madeira, como pode ser observado na Figura 3. A produção de alimentos também foi significativamente impactada no estado, uma vez que 16,8\% das falências, entre 2006 e 2016, ocorreram neste segmento.

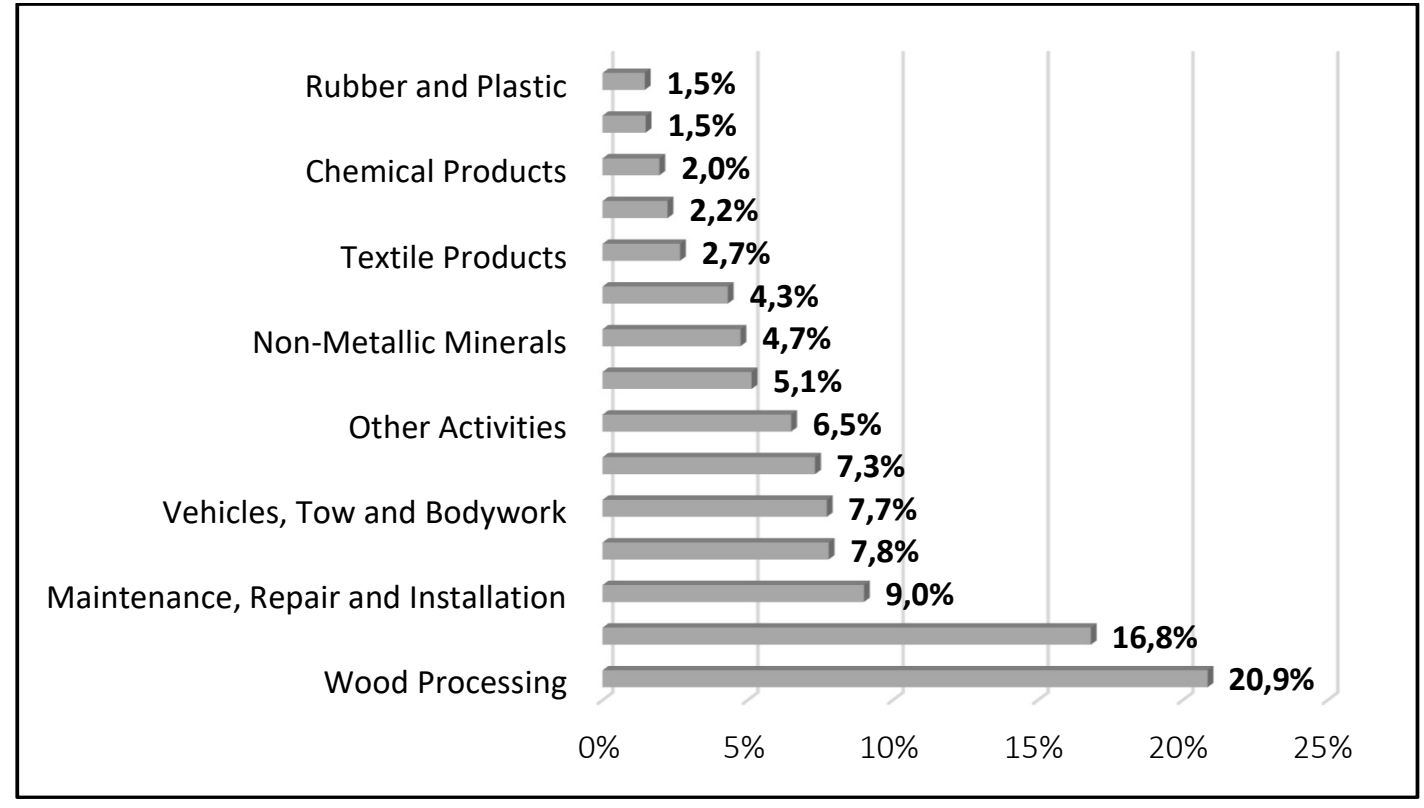

Figura 3: Atividade Econômica das Indústrias de Transformação (2006-2016). Fonte: JUCEMAT (2017). 
Na sequência, os segmentos de manutenção, reparação e instalação com 9\%, vestuário 7,8\%, veículos reboques e carrocerias 7,7\% e metal 7,3\% somam um grupo intermediário, entretanto, significativo dentre os encerramentos de indústrias de transformação em Mato Grosso. Quando observada a distribuição espacial das indústrias encerradas no estado (Figura 4), cabe destacar a Região Sul, uma vez que 33,8\% das indústrias de transformação e 37,5\% das extrativas localizavam-se neste espaço. Trata-se algo natural, por ser esta região a abarcar a capital Cuiabá e Várzea Grande, principal aglomerado urbano de Mato Grosso; mesmo não operando no local, muitas empresas mantinham sua sede na capital.

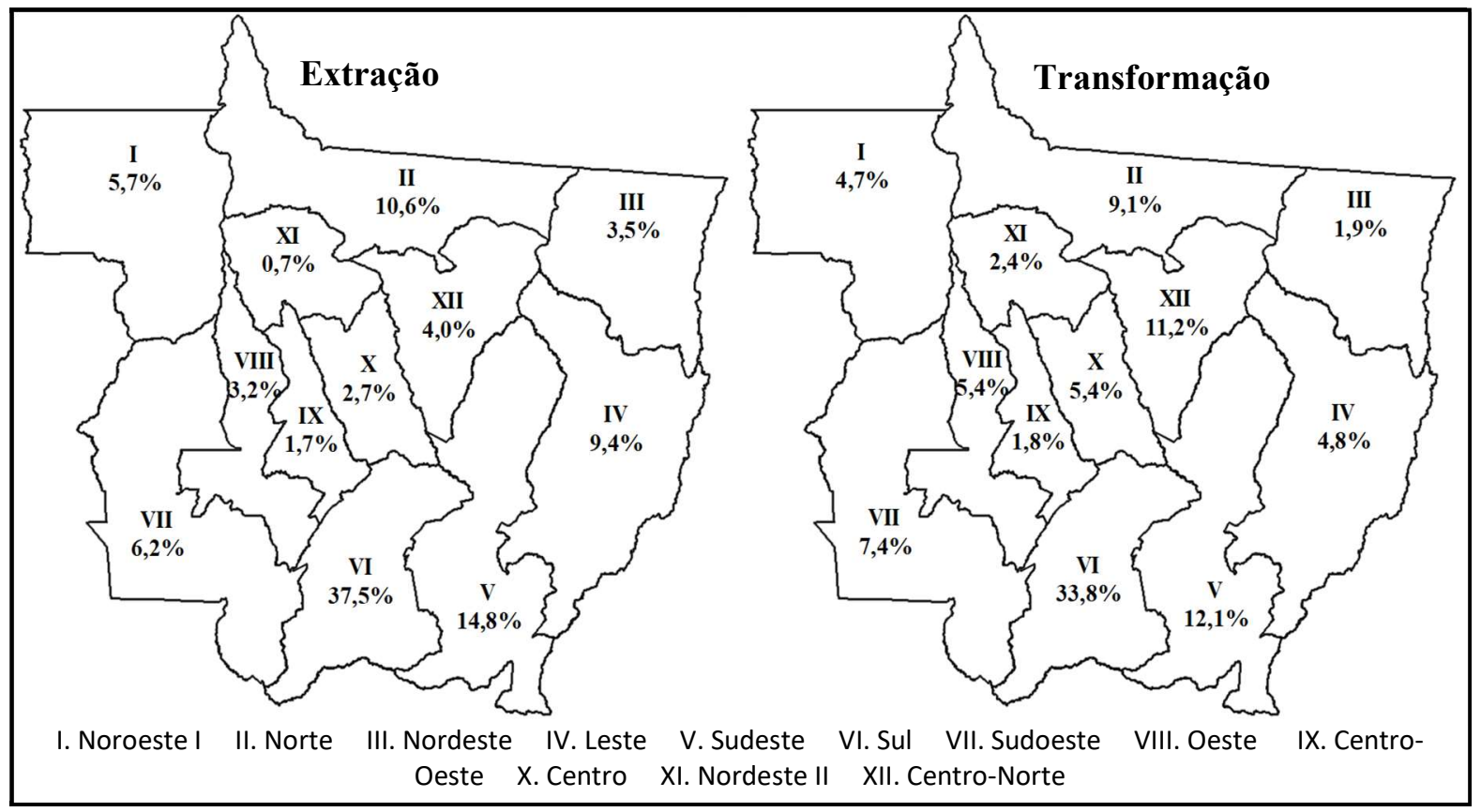

Figura 4: Distribuição Espacial das Empresas Falidas em Mato Grosso (2006-2016). Fonte: JUCEMAT (2017).

Outro local que merece destaque é a Região Sudeste, porta de entrada das principais rotas de transporte de Mato Grosso e principal acesso às regiões mais desenvolvidas do país. Neste corredor situa-se Rondonópolis, que ganhou status de segunda maior economia do estado e destaca-se pela sua industrialização na última década. A Região Centro-Norte é consideradas uma das principais regiões do agronegócio do estado, contudo foi uma das mais impactadas, principalmente no segmento de transformação, assim como a Região Norte, que acumulou enceramentos em ambos os setores. Na Região Leste, os impactos foram maiores no segmento extrativo, entretanto, todas as regiões apresentaram encerramentos no período.

Como já observado, a falência das empresas em Mato Grosso sofreu impactos das principais crises para o período em estudo, de modo que a taxa de sobrevivência, em parte, acompanha tais oscilações. Observa-se na Figura 5 que, anteriormente à 2006, as empresas apresentavam melhores indicadores de longevidade, atingindo $98,17 \%$ e $97,48 \%$, ante a crise do agronegócio mato-grossense de 2006 . O efeito negativo provocado na atividade econômica é muito claro entre as indústrias, evidenciado por uma súbita queda na sobrevivência para 57,32\% e 52,84\% entre 2006 e 2008. 


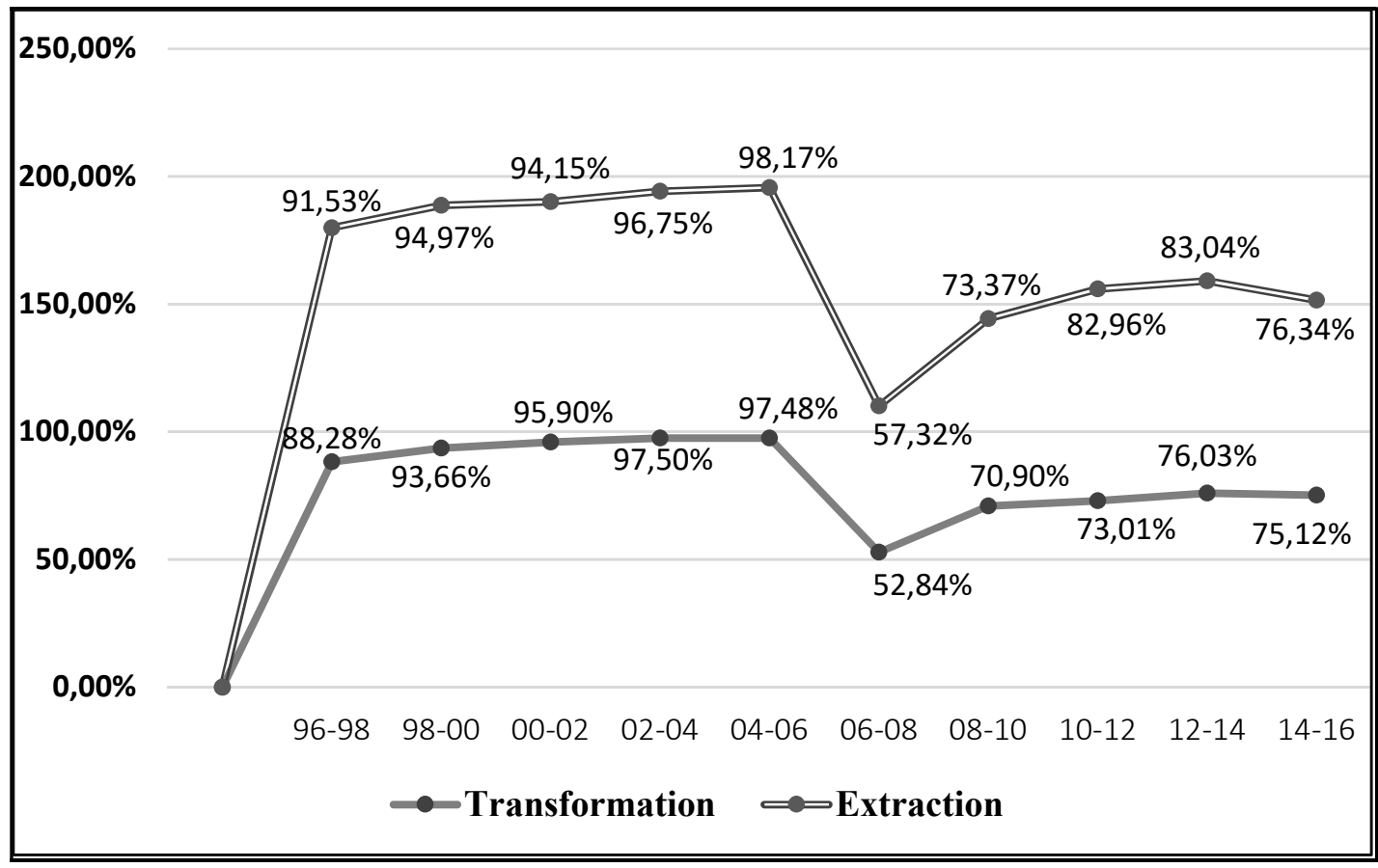

Figura 5: Taxa de Sobrevivência das Empresas de Mato Grosso (1996-2016). Fonte: JUCEMAT (2017).

A partir de 2008 a economia de Mato Grosso volta a reagir e os indicadores de sobrevivência das indústrias melhoram gradativamente. Cabe destacar que, em todas as crises houve muitas falências, no entanto, entre 2010 e 2016 também surgiram muitas empresas, mantendo certa estabilidade na taxa de sobrevivência. De certa forma, o setor de extração acusou mais a crise político-econômica enfrentada pelo país a partir de 2015, no entanto, o recuo não foi tão acentuado quanto 2006, sinal de que o setor industrial mato-grossenses condicionou-se melhor com o evento daquele ano, inclusive com melhora na sobrevivência em pleno efeito global devastador para muitos países do subprime, em 2010.

\section{CONSIDERAÇÕES FINAIS}

Os dados apresentados mostram que o setor industrial de Mato Grosso foi impactado pelos principais eventos negativos ocorridos na economia internacional e brasileira das últimas décadas. Destaca-se também, que a crise econômico-política em 2015 provocou o maior número de falências, tanto no segmento de extração quanto no segmento de transformação, contudo, o subprime e a crise do agronegócio de 2006 também acentuaram os problemas para o setor. Independentemente do nível de desenvolvimento industrial e solidez empresarial, adventos desta natureza tendem a causar impactos negativos; as dificuldades não circundam apenas o estado, ou tão somente apresentaram impacto local, pois em muitas regiões do país e do mundo foram registrados expressivos índices de encerramentos de empresas.

Dentre as estruturas impactadas, os efeitos foram mais agressivos para as microempresas, ao se considerar que mais da metade das indústrias falidas no estado apresentavam esta característica. Considerando as principais atividades extrativas de Mato Grosso, o maior impacto foi observado no segmento de extração de areia, cascalho e pedregulho, que representou um quarto das falências, também influenciado pela saturação no setor da construção civil e pela falta de recursos para manter parte das obras 
de infraestrutura no estado. Também, agravou o problema das indústrias de transformação de madeira, um dos principais segmentos da economia local.

Naturalmente, quando observada a distribuição espacial das indústrias encerradas em Mato Grosso, os maiores índices de encerramento são identificados na Região Sul, onde localizam-se a capital Cuiabá e Várzea Grande, com seu Distrito Industrial. Trata-se dos dois municípios com maior densidade populacional e, por muitos anos, as duas maiores economias do estado. Atualmente, o posto de segunda maior economia pertence à Rondonópolis, devido à sua industrialização na última década e sua posição estratégica no território. Localizado na Região Sudeste, o município é porta de entrada dos principais acessos ao estado, ponto de encontro das duas principais rodovias que ligam ao Centro, Sul e Sudeste e detém o maior entreposto ferroviário para escoamento de grãos. O processo de industrialização foi mais acelerado na última década e, por isso, as indústrias da região também sofreram com os problemas do setor nos períodos citados.

Os indicadores de longevidade da indústrias mato-grossenses sempre foram elevados e superiores a $90 \%$ até a primeira grande crise regional em 2006. O efeito negativo provocado na atividade econômica é muito claro entre as indústrias, evidenciado por uma súbita queda na sobrevivência para pouco mais da metade entre 2006 e 2008. Período em que ambos os segmentos foram impactados, contudo, em relação a crise político-econômica enfrentada pelo país a partir de 2015, o setor de extração acusou mais dificuldade, com ligeira que na sobrevivência de suas indústrias. O segmento de transformação encontra-se estável, assim como no período do subprime todas as empresas de Mato Grosso mantiveram-se; uma fase difícil para a economia nacional e, principalmente, internacional. Apesar do registro de dificuldades em algumas atividades, a indústria mantém certa solidez após a primeira grande crise de 2006.

Contudo, houve o registro de um número expressivo de falências em Mato Grosso, algo que preocupa o setor e estimula um estudo mais detalhado para compreender os motivos internos, inerentes à gestão, mercado e outros elementos cruciais para a permanência das indústrias no mercado. A maioria das empresas que encerraram atividades são de pequeno porte, muito devido ao fato de não possuírem a consistência empresarial mínima para enfrentar uma concorrência mais globalizada. Os custos operacionais tendem a ser elevados, a ponto de interferir na competitividade devido a estrutura logística precária, assim como, insuficiência de capital de giro. $O$ excesso de estoque, em virtude da retração na demanda em períodos de crise, pode ser um elemento importante, no entanto, apenas um estudo junto às indústrias encerradas poderia efetivamente apontar os principais fatores responsáveis pelos encerramentos.

\section{REFERÊNCIAS}

ALBUQUerque, A. A.. Fatores de Mortalidade de Pequenas Empresas: análise de empresas do setor varejista a partir do ciclo de vida organizacional. Tese (Doutorado em Engenharia de Produção) - Universidade de São Paulo, São Carlos, 2013.

ALVES, F. P.; LISBOA, W. T.. Vida e Morte da Pequena Empresa no Brasil: aspectos conceituais e contextuais com vistas ao reposicionamento estratégico. Revista Cesumar, v.19, n.2, p.479-500, 2014.
CHÉR, R. A.. Gerência das Pequenas e Médias Empresas. 2 ed. São Paulo: Maltese, 1991.

CHIAVENATO, I.. Empreendedorismo: dando asas ao espírito empreendedor. São Paulo: Saraiva, 2008.

CHURCHILL, N. C.; LEWIS, V. L.. Business Growth the Five Stages of Small Business Growth. Harvard Business Review, v.61, n.3, p.30-50, 1983 
COPE, J.. Entrepreneurial Learning from Failure. Journal of Business Venturing, v.26, n.6, p.604-623, 2011. DOI: http://doi.org/10.1016/i.jbusvent.2010.06.002

DEGEN, R. O.. Empreendedor: fundamentos da iniciativa empresarial. São Paulo: Pearson Education, 2005.

INE. Instituto Nacional de Estadística. Indicadores de Demografia Empresarial. 2017.

MINTZBERG, H.; LAMPEL, J.; QUINN, J.B.; GHOSHAL S. O Processo da Estratégia: conceitos, contextos e casos selecionados. 4 ed. Porto Alegre: Bookman, 2006.

OECD. Organisation for Economic Co-Operation and Development. Employer Enterprise Survival Rates. 2017.

PAIVA, M. J. G.; RAMALHO, R. X.. Constituição e Extinção de Microempresas em Juazeiro do Norte-Ce. Cadernos de Pesquisa, v.20, n.3, p.26-33, 2013. DOI:

http://doi.org/10.18764/2178-2229.v20n3p26-33
PINDYCK, R. S.; RUBINFELD, D. L.. Microeconomia. 7 ed. São Paulo: Prentice Hall, 2010.

TELLES, R.. Marketing Empresarial. São Paulo: Saraiva, 2003.

TOLEDO, P. F. C. S.; ABRÃO, C. H.. Comentários à Lei de Recuperação de Empresas e Falência. 5 ed. São Paulo: Saraiva, 2012.

WILCOX, J. W.. A Simple Theory of Financial Ratios as Predictors of Failure. Journal of Accounting Research. v.9, n.2, p.389-345, 1971. DOI: http://doi.org/10.2307/2489944

WESTGAARD, S.; WIJST, V. D. Default Probabilities in a Corporate Bank Portfolio: a logistic model approach. European Journal of Operational Research, v.135, n.2, p.338-349, 2001. DOI: http://doi.org/10.1016/S03772217(01)00045-5

A CBPC - Companhia Brasileira de Produção Científica (CNPJ: 11.221.422/0001-03) detém os direitos materiais desta publicação. Os direitos referem-se à publicação do trabalho em qualquer parte do mundo, incluindo os direitos às renovações, expansões e disseminações da contribuição, bem como outros direitos subsidiários. Todos os trabalhos publicados eletronicamente poderão posteriormente ser publicados em coletâneas impressas sob coordenação da Sustenere Publishing, da Companhia Brasileira de Produção Científica e seus parceiros autorizados. Os (as) autores (as) preservam os direitos autorais, mas não têm permissão para a publicação da contribuição em outro meio, impresso ou digital, em português ou em tradução. 